Cumhuriyet International Journal of Education-CIJE

e-ISSN: 2147-1606

Vol 6 (1), 2017, 140 - 156

\title{
Identification of Classroom Teachers' Communication Qualities During The First Literacy Teaching
}

\author{
Aybala ÇAYIR
}

\section{Summary}

\section{INTRODUCTION}

Reading is a focal point strongly emphasized by the education systems in all countries over the world. Reading ability constitutes one of the most important skills that an individual will have throughout her life. It is also an important predictor of the future of a individual's educational success. It is very critical to learn how to read especially in the first years of the primary school (Stanovich, 1986). Because a child who cannot learn how to read in the early period, would not be a good reader. In reading success, however, teachers have a critical importance. The researchers state that qualified teachers are one of the most important factors in the learning success of the student, and effective and competent teachers are needed in establishing a successful educational system. It has been explained that teachers' personal characteristics, professional and pedagogical knowledge and teaching skills as well as their emotionally and socially instructive and sensitive aspects come to the forefront as the qualifications of effective teachers (Allen, 2003). Among these skills, the communication qualities are particularly emphasized.

The researchers also indicate that a healthy communication established between the teacher and the student contributes to an effective learning environment, and serves as a good learning support in schools. Also, the literature draws attention to the relationship between language, communication and reading skills (Kelly, 2005). Researches show that language skills of the students who can communicate effectively with their teachers are also positively affected by such effective communication.

\section{METHOD}

In the study, the case study approach which is a qualitative research method, was employed. A case study involves to conduct an in-depth data-based analysis on an event, individual, phenomenon or process (Creswell, 2007). Within the scope of this study, the communication qualities exhibited by the first-grade teachers working at primary schools were examined. The study sample consisted of ten teachers who work as first grade teachers in different primary schools located in the central district of Aksaray.

The research data were collected through observation and interview techniques. Each teacher was observed at three different days and hours during the first literacy teaching process. As the data collection tool, the Teachers' Communication Qualities Observation Form was employed, which was constructed by Karahaliloglu and Duman (2016).

\section{FINDINGS}

It was found that the teachers are aware of the fact that communication qualities constitute an important factor to succeed in the first literacy teaching. However, most teachers stated that they were not adequately qualified in using communication in a way to support the first literacy teaching. It was determined in line with the data obtained from observations and interviews that, whereas teachers are adequately qualified in terms of 
individual characteristics at the sub-dimension of communication qualities, they need to be supported at the sub-dimensions aiming to support the developing language skills, offer opportunities for language use and to introduce new words/concepts.

\section{RESULTS AND DISCUSSION}

This study was conducted to examine the communication qualities of classroom teachers in the first literacy teaching process. In line with the findings obtained from observations and interviews, it was seen that, during the first literacy teaching process, the teachers are active in communication behaviors that include individual characteristics, however, they remain passive in exhibiting behaviors that require higher-level communication qualities.

During the interviews, the teachers designated "communication" as one of the most important skills that a qualified teacher should have, and emphasized that communication is also effective in literacy teaching as it is in academic and social success. Also in other researches conducted, the instructors and academicians consider the communication skills as one of the critical factors for the success in education, training and literacy teaching practices.

The study showed that the experienced teachers displayed better communication skills. There are a number of studies showing that the experienced teachers can display higherlevel communication behaviors in classroom communication (Blömeke, Suhl, \& Kaiser, 2011). This research also maintained these notions in terms of teachers with little experience needed to support to use communication as an educational tool. 